1 Veterans Administration Co-operative Study Group on antihypertensive agents. Effects of treatment on morbidity in hypertension. II. Results in patients with diastolic blood pressure averaging 90 through $114 \mathrm{~mm}$ Hg. F $A M A$ 1970;213:1143-52.

${ }^{2}$ Report of Medical Research Council Working Party on Mild to Moderate Hypertension. Randomised controlled trial of treatment for mild hypertension: design and pilot trial. $\mathrm{Br}$ Med F 1977;i:1437-40.

${ }^{3}$ Hypertension Detection and Follow-up Programme Co-operative Group. Five-year findings of the hypertension detection and follow-up program. I. Reduction in mortality of persons with high blood pressure, including mild hypertension. F $A M A 1979 ; 242: 2562-71$.

4 Hypertension Detection and Follow-up Co-operative Group. Five-year findings of the hypertension detection and follow-up program. II. Mortality by race sex and age. $7 A M A 1979 ; 242: 2572-7$.

5 Peart WS, Miall WE. Hypertension and special clinics. $\mathrm{Br}$ Med $\mathcal{f}$ $1980 ; 280: 180$

- Report by the Management Committee. Initial results of the Australian Therapeutic Trial in Mild Hypertension. Clin Sci 1979;suppl 5:449-52.

\section{Prophylaxis of surgical wound sepsis}

Wound sepsis causes suffering and inconvenience and costs money. Patients spend extra days in hospital and need attention at home from their general practitioners and community nurses while their wounds discharge pus. And who can cost the catastrophe of an infected hip prosthesis or arterial graft? How do we reckon the inconvenience and danger of an incisional hernia resulting from deep sepsis in an abdominal wound ?

The rates of wound sepsis are so much lower after clean operations (such as orthopaedic procedures) than after potentially contaminated abdominal operations that they are seldom considered together. Yet the principles of prophylaxis are the same in both: prevent exogenous and endogenous contamination and use an antibiotic during the operation if contamination is unavoidable.

All surgeons like to think that their technique is impeccable, but settle-plates in the average plenum-ventilated operating theatre usually show aerial contamination by Staphylococcus epidermidis and occasionally Staph aureus. Such a lack of sterility is not acceptable in the laboratory, and Charnley ${ }^{1}$ did not think it acceptable for hip replacement operations. The use of laminar flow ventilation, segregation of the operating team, and wearing ventilated suits can reduce the amount of aerial contamination - and wound sepsis - to near zero in orthopaedic surgery. In such circumstances antibiotic prophylaxis is not needed. When a hip prosthesis fails, however, infection is probably present.

In abdominal operations, on the other hand, parietal contamination arises mainly from the incision of infected hollow viscera. In colorectal operations the risks can be reduced by sterilising the visceral contents so far as possible by a combination of mechanical cleaning (one of the most efficient and acceptable methods is to give the patient $100 \mathrm{~g}$ of mannitol to drink in 31 of water) and a short course of oral or parenteral antibacterial agents.

As long ago as 1942 Altemeier $^{2}$ investigated the pathogenicity of bacteria isolated from pus of patients with peritonitis due to perforation of the appendix. He found that pure cultures of aerobes or anaerobes caused little harm to rabbits and guineapigs when injected intraperitoneally but that mixed cultures were rapidly lethal. This work was confirmed by Kelly, ${ }^{3}$ who found pathogenic synergy between Escherichia coli and Bacteroides fragilis in subcutaneous wounds in guinea-pigs.
Clinical trials have confirmed the need for antimicrobial agents active against both aerobes and anaerobes if wound infection is to be prevented; single agents are ineffective. Patients who receive an aminoglycoside (neomycin or kanamycin) with either metronidazole or erythromycin for one or two days before operations on the colon have a lower incidence of sepsis than controls.

When parietal contamination is unavoidable, wound infection can be minimised by parenteral or intraincisional administration of antibiotics, but only if these are given immediately before or during the operation. As to which antibiotic to use, the answer is naturally one which is active against the expected contaminants. In the upper gastrointestinal tract these are principally streptococci and coliforms, sensitive to cephalosporins. In the colon most aerobic and anaerobic pathogens are susceptible to a combination of a cephalosporin or an aminoglycoside with metronidazole. The single-dose combination of cephaloridine with clindamycin, however, is no more effective a prophylactic in abdominal operations than is cephaloridine alone. ${ }^{4}$

The choice of antibiotic cannot be made solely by reference to the sensitivity in vitro of the bacteria thought most likely to be present. Only large controlled clinical trials can give reliable answers. Such trials take longer when the control group is getting the best standard treatment against which the new regimen is to be judged-but there is no place for the untreated or placebo-treated control group in these circumstances. Once trials have established that one method of prophylaxis is better than none, including an untreated group is no longer ethically justified.

We still do not know how many doses of antibiotic should be given. One or three doses, or a five, seven, or 14-day course? There have been very few trials to help the surgeon

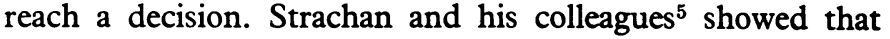
a single preoperative dose of cephazolin resulted in less wound sepsis after cholecystectomy than a seven-day course, and Pollard and his colleagues ${ }^{6}$ found that three doses of cephaloridine were as good as a 14-day course of flucloxacillin in patients having total hip replacements. There is far more danger of antibiotic-resistant bacteria emerging when long courses are given. Perhaps the rule should be not more than three doses, the first before operation and the others within 12 hours.

Among the many puzzling aspects of postoperative wound sepsis is the wide variation in the rates for similar operations reported from different centres. What is the explanation, for example, of rates of wound sepsis after elective cholecystectomy without antibiotic prophylaxis that vary from $2 \%$ in the United States to $6 \%$ in Australia and $22 \%$ in Britain?? Selective forgetfulness may occur in retrospective analyses, but surely not in prospective trials. Does the answer lie in different definitions of sepsis, different surgical techniques, or different kinds of patients ? Given a similar degree of operative parietal contamination, why do some patients get wound sepsis and others not? What bearing has the patient's immune state, and can we measure it adequately by studying recall antigen skin reactions and lymphocyte and neutrophil functions? Many questions still remain to be answered; perhaps after all we should, like Sir Ralph Bloomfield Bonington, start by learning to stimulate the phagocytes.

${ }^{1}$ Charnley J, Eftekhar N. Postoperative infection in total prosthetic replacement arthroplasty of the hip-joint with special reference to the bacterial content of the air of the operating room. Br 7 Surg 1969;56 : 641-9.

${ }^{2}$ Altemeier WA. The pathogenicity of the bacteria of appendicitis peritonitis. An experimental study. Surgery 1942;11:374-84. 
${ }^{3}$ Kelly MJ. Wound infection: a controlled clinical and experimental demonstration of synergy between aerobic (Escherichia coli) and anaerobic (Bacteroides fragilis) bacteria. Ann Roy Coll Surg Eng 1980;62:52-9.

4 Greenall MJ, Froome K, Evans M, Pollock AV. The influence of intraincisional clindamycin on the incidence of wound sepsis after abdominal operations. F Antimicrob Chemother 1979;5:511-6.

5 Strachan CJL, Black J, Powis SJA, et al. Prophylactic use of cephazolin against wound sepsis after cholecystectomy. Br Med f 1977;i:1254-6.

6 Pollard JP, Hughes SPF, Scott JE, Evans MJ, Benson MKD. Antibiotic prophylaxis in total hip replacement. Br Med F 1979; :707-9.

7 Watts JM, McDonald PJ, Hoffman CEJ. Prophylactic co-trimoxazole in biliary surgery. $\mathrm{Br} \mathrm{Med} \mathcal{F} 1979 ; \mathrm{i}: 58$.

\section{Aetiology of acquired cardiac valve lesions}

Even in the absence of a history of rheumatic fever, acquired valve lesions are commonly ascribed, both clinically and pathologically, to rheumatic heart disease. Recently this unitarian approach has been challenged clinically, ${ }^{1}$ and reappraisal urged of the revised Jones criteria ${ }^{2}$ for the diagnosis of rheumatic fever. ${ }^{34}$ Last year $\mathrm{Ward}^{5}$ re-examined the clinical features in acute and chronic heart disease to ascertain whether a single rheumatic aetiology seemed plausible.

The preliminary analyses indicated differences between those patients who developed carditis occurring in the absence of chorea, arthritis, or arthralgia and those in whom it was combined with polyarthritis. Patients with polyarthritis were then grouped into several categories: those with accompanying arthralgia, those under 9 years of age, those with enlargement of the heart, and those who had shown signs of polyarthritis or chorea. Patients with chorea were also separately analysed. The results of this analysis showed that patients with isolated carditis had symptoms directly referable to the heart (chest pain, breathlessness on exertion, and ankle swelling), while those with polyarthritis or chorea had no direct cardiac symptoms unless cardiac failure, pericarditis, or cardiomegaly supervened. Ward's conclusion ${ }^{5}$ was that in many cases of isolated carditis defined according to the revised Jones criteria ${ }^{2}$ (requiring only the presence of two minor manifestations, each of which is non-specific) there was no evidence of a rheumatic cause $^{3}$; by including such patients in the rheumatic fever group clinicians were obscuring important clinical differences.

Ward's second study ${ }^{5}$ looked at the chronic valve lesions of acquired heart disease, separating those patients with a history of rheumatic fever from those without such a history. The group with a positive history more commonly had aortic valve disease and mixed mitral stenosis and insufficiency, whereas isolated mitral stenosis without aortic valve disease occurred more commonly in those patients who had no such history. The differences were clear enough to permit him to distinguish which patients had had rheumatic fever.

No specific laboratory tests are available for rheumatic fever, but differences have been established in the human leucocyte antigen (HLA) pattern between patients with and without a history of rheumatic fever. ${ }^{6} 7$ Ward et al found that in patients without such a history antigens A29 and AW30/31 were more common. The differences in the clinical patterns of patients with acute valvulitis and chronic heart disease suggest that other causative agents, such as virus infections, may be important. Some clinical differences have already been suggested between rheumatic heart disease and viral carditis; one suggestion is that enlargement of the heart without murmurs is most likely due to viral infection, whereas aortic insufficiency is probably due to rheumatic heart disease. ${ }^{8}$

Neither routine morphological examination of excised valves nor necropsy studies give much guidance to the aetiology. A wide range of macroscopic changes has been documented in chronic valvular disease. ${ }^{9}$ Fibrous thickening, distortion or destruction of the normal architecture, and superimposition of thrombus are non-specific findings, which may occur in both congenital and acquired valve lesions. The only feature identifying the acquired conditions is the increased vascularity. ${ }^{10}$ The presence of Aschoff cells offers substantial evidence of a rheumatic aetiology, but they are rarely seen in chronically affected valves even of patients with a history of rheumatic fever. Virus lesions of valves have been clearly shown by immunofluorescence techniques, both in man and in animal studies. ${ }^{11-13}$ Unless such virological studies are undertaken and give negative results we should be cautious about ascribing chronic valvulitis to rheumatic heart disease at morphological examination, particularly if there is no history of rheumatic fever or if damage to the valve has been mild.

The balance of evidence seems to have tilted against the unitary theory, and in future other causes should be considered in patients with acquired valvular lesions and no history of rheumatic fever. Virus infections seem likely to prove responsible for at least some of these cases.

1 Ward C, Ward AM. Virus antigen in valvular heart disease. Lancet 1974; i:755-6.

${ }^{2}$ Stollerman GH, Markowitz M, Taranta A, Wannamaker LW, Whittemore R. Jones criteria (revised) for guidance in the diagnosis of rheumatic fever. Circulation $1965 ; 32: 664-8$.

${ }^{3}$ Ward C. Observations on the diagnosis of isolated rheumatic carditis. $\mathrm{Am}$ Heart F 1976;91:545-50.

${ }^{4}$ Louis-Gustave A. Concerning rheumatic fever and rheumatic heart disease. Am Heart $\mathcal{F}$ 1977;93:536.

5 Ward C. A reappraisal of the clinical features in acute and chronic rheumatic heart disease: etiological implications. Am Heart $\mathcal{f} 1979 ; 98$ : 298-306.

${ }^{6}$ Ward C, Gelsthorpe K, Doughty RW, et al. HLA antigens and acquired valvular heart disease. Tissue Antigens 1976;7:227-31

7 Ward C, Celstorpe K, Doughty RW. A relation between HLA antigens and clinical features in patients with acquired valvular heart disease. Br Med f 1976;i:1499-501.

${ }^{8} \mathrm{Kloth} \mathrm{HH}$. Acute rheumatic fever and viral carditis. Am Heart $\mathcal{f}$ 1977; 93:133-4.

${ }^{9}$ Rusted IE, Scheifley CH, Edwards JE. Studies of the mitral valve. II Certain anatomic features of the mitral valve and associated structures in mitral stenosis. Circulation 1956;14:398-406.

${ }^{10}$ Olsen EGJ. The pathology of the heart. New York: Intercontinental Medical Book Corporation, 1973.

11 Burch GE, Sun SC, Colcolough HL, Sohal RS, De Pasquale NP. Coxsackie $B$ viral myocarditis and valvulitis identified in routine autopsy specimens by immunofluorescent techniques. Am Heart $\mathcal{F}$ 1967;74: 13-23.

12 Burch GE, Colcolough HL. Viral valvulitis. Am Heart $\mathcal{f}$ 1969;78:119-23.

${ }^{13}$ Burch GE, Tsui CY. Evolution of coxsackie viral valvular and mural endocarditis in mice. Br $\mathcal{F}$ Exp Pathol 1971 ;52:360-4.

\section{Industrial action affects the "BMJ"}

Industrial action in connection with a national dispute in the printing industry has seriously delayed the publication and dispatch of the BMF. The number of pages in this issue has also been reduced and regrettably it has not been possible to publish the Annual Report of Council(seep 1093). Weapologise to readers for these inconveniences, which are likely to continue until the national dispute is settled. 